\title{
Optimization of the Parameters for the Molding Process of Small-Size Rice Straw Insulating Blocks via Response Surface Methodology
}

\begin{abstract}
Weili Yuan, Anhong Bao, * Xinlei Han, and Qiu Luo
Rice straw, which is considered an excellent insulation material, can be filled into the hollows of concrete block after being pressed, thereby improving the thermal performance of the concrete block. This new type of straw-concrete composite block will have good mechanical and thermal properties. In this study, to explore the feasibility of this new type of block, the response surface method was introduced. The goal was to find the effects of processing parameters on the forming quality of straw blocks. The quadratic regression model was established, and the processing parameters were optimized. It was found that the forming density, vertical pressure, pressure-holding time, and the interaction between the forming density and pressure-holding time had significant effects on the forming quality of the straw blocks. The optimal conditions obtained by RSM optimization were a forming density, a vertical pressure, and a pressureholding time of $319.7 \mathrm{~kg} / \mathrm{m}^{2}, 2.5 \mathrm{kN}, 33.68 \mathrm{~s}$, respectively. Under these conditions, the volumetric contractivity of straw blocks was $11.17 \%$, the horizontal failure strength was $21.74 \mathrm{kPa}$, and the natural moisture content was $16.37 \%$. The parameters calculated via the prediction model were highly consistent with the results produced via the actual measurements, which showed that the prediction model was reliable and potentially useful in guiding industrial production.
\end{abstract}

Keywords: Rice straw; Forming density; Volumetric contractivity; Response surface methodology

Contact information: College of Engineering and Technology, Southwest University, Chongqing 400715

China; *Corresponding author: bah69@qq.com

\section{INTRODUCTION}

Insulation materials for the construction of housing has attracted the attention of researchers who are striving to find a path to alleviate the conflict between nature and human beings. The usage of environmentally friendly materials, especially those produced from local raw materials, could greatly contribute to decreasing the overall emissions of greenhouse gases (FAO 2019). In China, rice is one of the most widely grown food crops, and China generates the most rice out of all the rice-growing countries, according to the database of the Food and Agriculture Organization of the United Nations (Fig. 1). Statistics indicate each ton of rice produced would generate 1 ton to 1.5 tons of rice straw, which means that China is extremely rich in rice straw resources (Bi et al. 2011).

Rice straw was considered an agricultural waste in the past, but it is also a type of biomass material. The composition of the rice straw varies according to breeds and regions, but all rice straw consists of lignins, cellulose, hemicellulose, and ash. Rice straw can be considered as a fibrous porous material, and the inner fiber structure is coated with a complicated net structure consisting of lignins and cellulose. These structural features 
provide rice straw with a strong heat-retaining capacity and hygroscopic ability. The hygroscopicity affects the balance of indoor temperature and humidity, thereby making people feel more comfortable (Conti et al. 2016).

\section{Top 10 Rice Production Countries in the World}

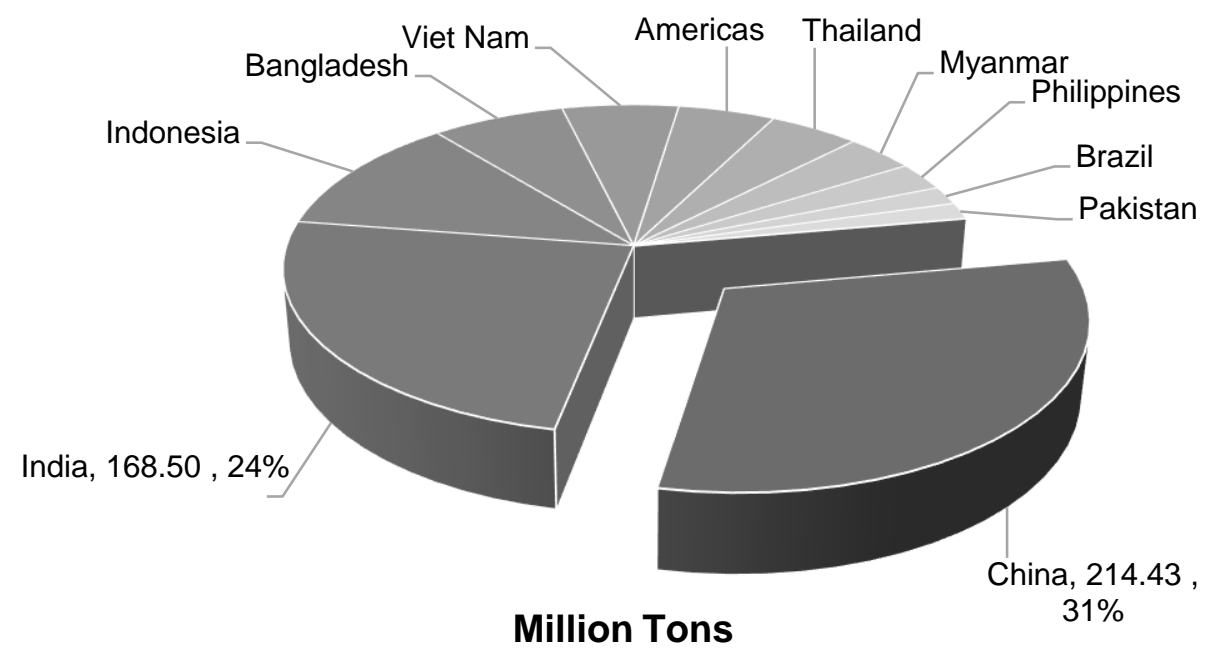

Fig. 1. Rice production levels of various countries in the world

Based on these considerations, the usage of rice straw as a construction material has been found to be a viable alternative for residential or agricultural construction. Compared to traditional construction materials, e.g., brick and concrete, rice straw houses may provide lighter weight, lower heating energy loads, and higher-quality physical properties, e.g., sound insulation and seismic stability (Schiavoni et al. 2016). While synthetic products still account for more than $90 \%$ of the market for traditional thermoacoustic insulators (Asdrubali et al. 2015), their remaining disadvantages, i.e., unsustainable production and emission of greenhouse gases, cannot be ignored (Thomson and Walker 2014).

China is a fast-growing developing country with a large population that generates a huge amount of rice straw. Making use of the rice straw as a construction material not only can serve as a way to recycle the rice straw and offer comfortable living spaces, but it also offers energy savings and reduces the air pollution caused by burning the rice straw (Li et al. 2008; Kim and Ward 2019). The most common design for using rice straw in construction is using rice straw bales as a primary structural element. There are multiple designs and construct processes that have been developed in recent years. Classically, rice straw was formed into a bale with an average length of $80 \mathrm{~cm}$ to $100 \mathrm{~cm}$ and a density of $100 \mathrm{~kg} / \mathrm{m}^{3}$ to $150 \mathrm{~kg} / \mathrm{m}^{3}$, using a straw baler and a pressure molding machine (Palermo et al. 2014; Lecompte and Le Duigou 2017; Maraldi et al. 2017; Garas et al. 2009). According to the stress conditions of straw bale, the straw bale construction could be divided into load-bearing and non-load-bearing straw bale. The non-load-bearing rice straw construction usually uses wood, concrete, or steel to construct the column and beam of the house and fills the walls with rice straw bales (Li et al. 2008; Jones 2009). To increase the monolithic stability of rice straw construction, pinning systems are introduced to connect each bale, as well as the bale and column (Holzhueter and Itonaga 2014; Yin et al. 2018). Subsequently, mortar or lime rendering is applied to the straw bale wall, which improves 
the appearance as well as ameliorating the hygrothermal environment (Holzhueter and Itonaga 2014).

As implied by early studies, thermal properties of a material are usually measured by thermal conductivity and thermal diffusivity. In some recent works, the classical measurement technique of the thermal properties, the guarded hot plate apparatus, while not as simple and quick as the transient techniques, is still widely used to test the thermal properties of straw bale, since it still provides benefits in terms of its accuracy. Goodhew and Griffiths (2004) reported a thermal conductivity of $0.067(0.002) \mathrm{W} \cdot \mathrm{m}^{-1} \cdot \mathrm{K}^{-1}$ for straw bales with an average density of $60 \mathrm{~kg} \cdot \mathrm{m}^{-3}$. Wei et al. (2015) introduced a high-frequency hot-pressed strawboard with a thermal conductivity of $0.052 \mathrm{~W} \cdot \mathrm{m}^{-1} \cdot \mathrm{K}^{-1}$. However, many factors could lead to variation in thermal conductivity. For example, many studies have already shown the relation between the density and the thermal conductivity of straw bales (Ashour 2003; Vèjelienè 2012; Costes et al. 2017). In 2016, Palumbo et al. (2016) proposed that the thermal conductivity of straw bales is related to the ambient relative humidity. Carfrae (2011) introduced the concept of the effects of compaction of the moisture content in rice straw on the hygroscopic properties of the straw bales. Moreover, the void space between each bale, as well as the orientation of fibers, could also influence the thermal properties of the straw bale. But it is noteworthy that Chaussinand et al. (2015) reported thermal conductivity of rice straw bale material in a range of $0.052 \mathrm{~W} \cdot \mathrm{m}^{-1} \cdot \mathrm{K}^{-1}$ to $0.12 \mathrm{~W} \cdot \mathrm{m}^{-1} \cdot \mathrm{K}^{-1}$.

Overall, the construction of straw bale buildings, as well as their hygrothermal properties, have been sufficiently studied and an increased number of straw bale constructions have been reported all over the world. However, traditional straw bale construction was not able to increase its application rate against the increasing straw production rate in China, especially in the southern region, for which the reasons could be as follows:

(1) The average length of a straw bale has been reported to exceed $80 \mathrm{~cm}$ in many studies (Krick 2008; Vardy and MacDougall 2013; Lecompte and Le Duigou 2017; Maraldi et al. 2017), which is quite large. The large straw bale blocks would increase the volume of the structural component and compress floor space, as well as limit the extension of the floorplan, which would be undesirable, considering the lack of land faced by many Chinese cities. However, large structural elements require a hoisting machine to install and more trained workers to operate, which is hard to provide in the Chinese countryside.

(2) The climate in the south of China is rainy and humid, which can cause considerable harm to the straw bale. Traditional mortar rendering or wooden board coating may not protect the straw from water very well when it is being subjected to a long-lasting rainfall. As a result, the straw will be softened and become subjected to mildew in a humid ambient environment, losing its strength and hygrothermal properties, as well as decreasing the durability of the material.

(3) The production, transportation, and use of straw bale require specific large straw balers and cranes. These machines require extra workers to operate, of which the additional labor costs could not be ignored. The total cost of straw bale construction is not cheap enough to challenge the position of classical brick and concrete structures.

Therefore, the authors have developed a new type of straw-concrete composite block. This kind of composite block is produced by filling a small-sized hollow concrete block with rice straw blocks made with rice straw pretreated with a low concentration of $\mathrm{NaOH}$ via manual work or compress tester. The blocks are made of concrete to provide 
physical strength and the role of the straw is to improve thermal performance. Straw is isolated from the air due to the protection of concrete, which can effectively avoid dampness, mildew, insects, and other problems, and improve the durability of materials. Therefore, this type of material not only has appreciable strength and hygrothermal properties but also possesses better waterproofing abilities and durability. For further understanding and applications of this composite block, the following issues were studied:

(1) Introduction of an improved rice straw pretreatment method and straw block low-pressure forming process; and (2) Evaluation of the volumetric contractivity, horizontal failure strength, and natural moisture content of the straw blocks formed under various conditions and assess the impaction of each variable.

\section{EXPERIMENTAL}

\section{Rice Straw Preparation}

The rice straw (XiDaYou216) was obtained from an experimental farm at the Southwest University in Chongqing, located at $106.40^{\circ} \mathrm{E}, 29.80^{\circ} \mathrm{N}$, in southwest China. The rice straw was selected, cleaned, and trimmed into small pieces $(1 \mathrm{~cm}$ to $2 \mathrm{~cm})$ with a grass cutter (Xianglong Hardware Machinery, Shandong, China) and put into a series heatdrying oven (DHG-9245A) at a temperature of $60{ }^{\circ} \mathrm{C}$ to ensure dryness. The pretreatment method, which was previously used by the authors, was to soak the straw in $1 \%$ concentration $\mathrm{NaOH}$ solution ( $\mathrm{w} \geq 96 \%$ ) (Chuandong Chemical Industry Ltd., Chongqing, China) for $6 \mathrm{~h}$. The $\mathrm{NaOH}$ could dissolve the hydrophobic wax layer and the irregular protrusion on the surface of straw fibers, which made the surface smooth. The straw could be in full contact with water and become soft and hydrophilic. The contact area between the fiber molecules of straw is thereby increased, and the adhesion between straw pieces also is increased so that the self-bonding property is improved (Han et al. 2019; Sun et al. 2020). After pretreatment, the mass loss rate of the rice straw was $7.82 \%$. However, this pretreatment method has the following defects: (1) the pretreatment time is too long, which is not conducive to industrial production; and (2) the total water consumption of soaking the straw is large, and more waste liquid is produced during the pressing process. Therefore, to solve the above problems, the authors adopted an improved pretreatment method for this experiment. The water consumption was reduced when the $\mathrm{NaOH}$ solution was configured, and the ratio of straw to water was reduced from 1: 5 to $1: 2$, while the concentration of the $\mathrm{NaOH}$ solution remained unchanged. Meanwhile, the straw was soaked with the addition of mechanical stirring for $20 \mathrm{~min}$ to ensure the straw was fully soaked. The experiment showed that the mass loss rate of rice straw treated via this method reached $6 \%$ to $7 \%$, which had a minimal difference from the previous pretreatment method, but the treatment efficiency was increased, and the volume of polluted waste liquid output was greatly reduced. Therefore, from the perspective of industrial production, the novel pretreatment method from this experiment is better.

\section{Molding Technology of the Straw Blocks}

The molding pressure was applied via a YAD-2000 microcomputer-controlled electron universal tester, as shown in Figs. $2 \mathrm{a}$ and $2 \mathrm{~b}$. The pressure loading speed was set at $0.1 \mathrm{kN} / \mathrm{s}$. First, the rice straw was pressed slowly by the universal tester to squeeze excess water after being soaked in the $\mathrm{NaOH}$ solution. Then, the rice straw was filled into a customized wooden mold (130 $\mathrm{mm}$ x $130 \mathrm{~mm}$ x $190 \mathrm{~mm})$. Next, the pressure head of the 
universal tester was moved downward with the beam in order to press the straw into a straw block. Finally, the wooden mold was removed after $24 \mathrm{~h}$, and the straw block was allowed to cure at a standard atmosphere and temperature for 28 days. The molded straw block is shown in Fig. 2c.

a)

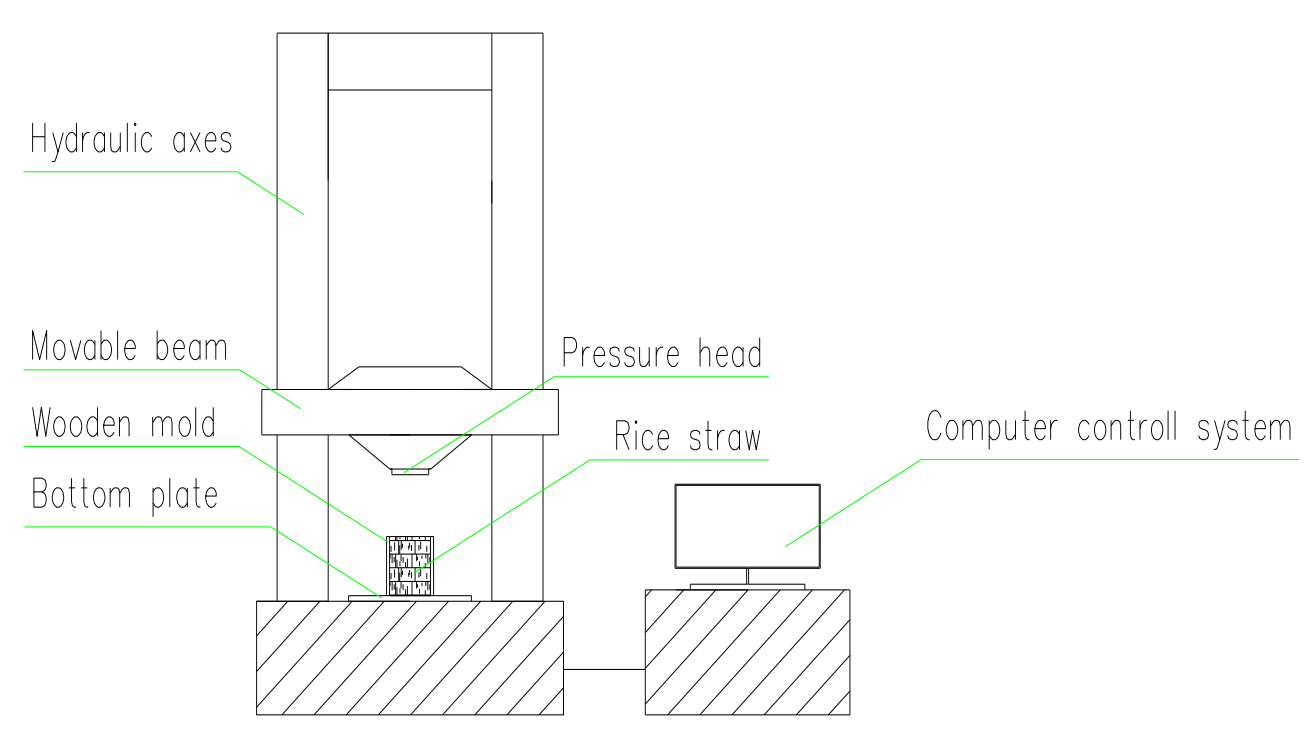

b)

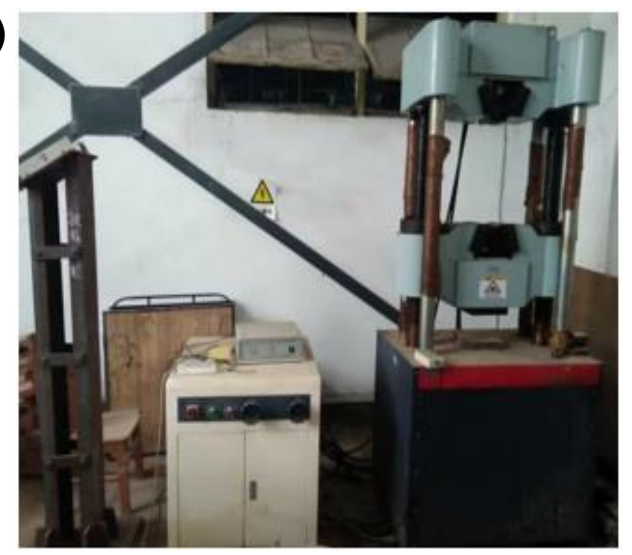

c)

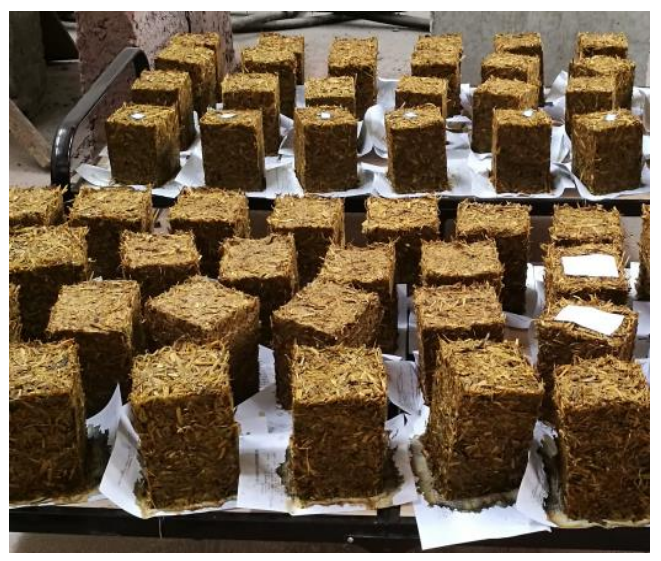

Fig. 2. a), b) Experimental system for rice straw blocks molding optimization and c) rice straw blocks

\section{Optimum Molding Parameters}

The study was carried out to determine the constant parameters, i.e., the forming density, vertical pressure, and the pressure-holding time in the molding process. These parameters were determined to obtain the optimum molding block.

\section{Forming density}

Forming density represents the density as well as the ramming level of the straw blocks, which plays an important role in the strength of the block, as well as its durability. The forming density can be calculated using Eq. 1,

$$
\rho_{D}=M / V
$$

where $\rho_{D}\left(\mathrm{~kg} / \mathrm{m}^{3}\right)$ is the forming density of the straw blocks, $M(\mathrm{~kg})$ is the weight of the 
straw required for a single block, and $V\left(\mathrm{~m}^{3}\right)$ is the volume of the wooden mold.

Vertical pressure

The vertical pressure determines an indispensable part of the molding effect. The preliminary experiment demonstrated that a vertical pressure of $2.5 \mathrm{kN}$ to $3.5 \mathrm{kN}$ yielded straw blocks with a good performance.

\section{Pressure-holding time}

The pressure-holding time also plays an important role in the molding process. If the holding time is too short, the formation of a stable bond between the straw fibers could not occur, such that the density of blocks cannot reach the expected value. However, if the holding time is too long, the inner structure of the straw block may be destroyed. Both of these outcomes are harmful to the final molding effect.

\section{Evaluation Evidence of the Molding Quality}

To determine the impact of various molding parameters on the quality of the straw block molding process, the volumetric contractility of the straw block after pressure molding, the horizontal failure strength, and the natural moisture content were determined to evaluate the straw block.

\section{Volumetric contractivity}

After the pressure molding process, the volume of the straw block demonstrated a contraction phenomenon; a smaller contracted value $(\eta)$ indicated a better molding effect. The volumetric contractivity can be defined by Eq. 2,

$$
\eta=\frac{V_{0}-V_{t}}{V_{0}} \times 100 \%
$$

where $\eta(\%)$ is the volumetric contractivity of the blocks, $V_{0}\left(\mathrm{~kg} / \mathrm{m}^{3}\right)$ is the initial volume of the straw block when it is formed, and $V_{t}\left(\mathrm{~kg} / \mathrm{m}^{3}\right)$ is the volume of the block after curing for $28 \mathrm{~d}$.

\section{Horizontal failure strength}

Due to the vertical pressure molding methodology, the straw blocks are compressed a lot, which generates greater elastic deformation in comparison to plastic when vertical pressure is applied.
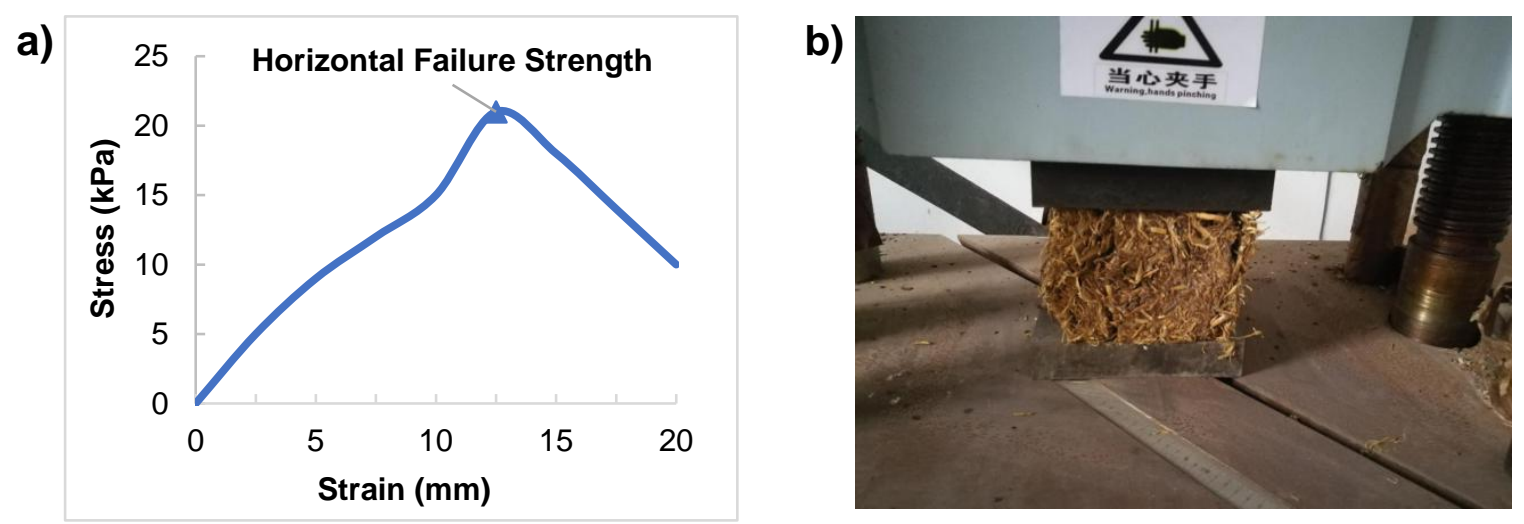

Fig. 3. Sample of a stress-strain curve (a); and the hierarchical destruction of the straw block (b) 
After removing the pressure, the blocks would recover a portion of the deformation and become more difficult to destroy. However, the straw blocks are predicted to incur hierarchical destruction when too great a pressure is applied. The horizontal failure strength $(H F S)$ was measured with an automatic pressure tester after curing the straw blocks for 28 $\mathrm{d}$. The straw block shows notable hierarchical destruction and observable cracks between each horizontal section. Also, the stress-strain curve gradually rises and finally reaches the top, which indicated the horizontal failure strength of the straw block (Fig. 3).

\section{Natural moisture content}

After pretreatment with $\mathrm{NaOH}$ solution, some parts of the straw will degrade, which leads to a decrease in cohesion between the molecules, thus increasing the accessibility of the straw fiber to the air (Han et al. 2019). The pretreatment process makes the straw fiber prefer to absorb the water in the air, which leads to an increase in the weight of the straw block after curing in ambient conditions. During the final phase of the curing process, the moisture of the blocks would reach a dynamic balance. However, a high moisture content balance level is harmful to the strength and durability of the straw blocks, so the natural moisture content $(N M C)$ should be limited via the molding process conditions. The $N M C$ can be calculated by Eq. 3,

$$
N M C=\frac{m_{1}-m_{2}}{m_{1}} \times 100 \%
$$

where $N M C(\%)$ is the natural moisture content of blocks, $m_{1}(\mathrm{~kg})$ is the weight of the blocks after curing for $28 \mathrm{~d}$, and $m_{2}(\mathrm{~kg})$ is the constant weight acquired from blocks dried in a series heat-drying oven at a temperature of $50{ }^{\circ} \mathrm{C}$ for $24 \mathrm{~h}$.

\section{Design of the Single Factor Experiment}

The single factor effects of forming density, vertical pressure, and pressure-holding time on the quality parameters of the straw block were investigated. The forming density was set to $240,280,320,360$, and $400 \mathrm{~kg} / \mathrm{m}^{3}$. Vertical pressure was set to $1.5,2.0,2.5,3.0$, and $3.5 \mathrm{kN}$. Pressure-holding time was set to 10, 30, 50, 70, and 90s.

\section{Design of the Box-Behnken Experiment}

A Box-Behnken experimental design was introduced with a total of 17 experiments, with 12 analysis points to study the molding quality, and with 5 replicates at the central point to estimate error (Wang et al. 2006). According to the results of the single factor experiment, three variables studied were the forming density $\left(\mathrm{X}_{1}\right)$, the vertical pressure $\left(\mathrm{X}_{2}\right)$, and the pressure-holding time $\left(\mathrm{X}_{3}\right)$, which were demonstrated in a reasonable range. To alleviate the impact of having various dimensions on the data analysis processing, three levels were selected for each independent variable and coded as $(-1,0,1)$; the natural and coded values for the independent variables are summarized in Table 1. The levels were coded according to Eq. 4, and the experimental data was fit using the polynomial equation in Eq. 5,

$$
\begin{aligned}
& X_{i}=\left(x_{i}-x_{0}\right) / \Delta x \\
& Y_{i}=\beta_{0}+\sum_{i=1}^{3} \beta_{i} X_{i}+\sum_{i=1}^{3} \beta_{i i} X_{i}^{2}+\sum_{i=1}^{3} \sum_{j=i+1}^{3} \beta_{i j} X_{i} X_{j}
\end{aligned}
$$

where $X_{i}$ is the code value of each independent variable, $x_{i}$ is the true value of each independent variable, $x_{0}$ is the true value of each independent variable on the experimental central point, $\Delta x$ is the step variation of each independent variable, $Y_{i}$ is the response value 
of the quality evidence, $\beta_{i}$ is the coefficient of the linear terms, $\beta_{i i}$ is the coefficient of the quadric terms, and $\beta_{i j}$ is the coefficient of the interaction terms.

Table 1. Design of the Experimental Factors and Levels

\begin{tabular}{|c|c|c|c|}
\hline Code Levels & $\begin{array}{c}\text { Forming density } \\
\left(\mathrm{kg} / \mathrm{m}^{3}\right)\end{array}$ & Vertical Pressure $(\mathrm{kN})$ & $\begin{array}{c}\text { Pressure-holding } \\
\text { time }(\mathrm{s})\end{array}$ \\
\hline 1 & 360 & 3.5 & 50 \\
\hline 0 & 320 & 3.0 & 30 \\
\hline-1 & 280 & 2.5 & 10 \\
\hline
\end{tabular}

The regression coefficients of the mean, linear, interaction, and quadratic terms, $\left(\beta_{0}\right.$, $\beta_{i}, \beta_{i i}$, and $\beta_{i j}$ ) were respectively calculated from the experimental results via the leastsquares method. The $X_{i}$ and $X_{j}$ are the independent variables in coded values, which ranged from -1 to 1 . Response surface methodology analysis software (Design Expert 10, Stat-Eae Inc., Minneapolis, MN) was introduced to analyze the results and optimize the molding conditions. Three optimal response values were tested to check the validity of the model.

\section{RESULTS AND DISCUSSION}

\section{Result of the Single Factor Experiment}

In order to study the influence of forming density on the quality parameters of the straw block, the vertical pressure was set as $2.5 \mathrm{kN}$, and the pressure-holding time was set as $30 \mathrm{~s}$. The results of the single factor test are shown in Fig. 4. As can be seen from Figs. $4 \mathrm{a}$ and $4 \mathrm{~b}$, when the forming density increased, the volumetric contractivity of the straw block gradually decreased, while the horizontal failure strength gradually increased, and reached the minimum and maximum value at $320 \mathrm{~kg} / \mathrm{m}^{3}$ respectively. This is because when the density increases, the bonding between the straw fibers is more compact, forming a compact and stable structure. This tends to resist volumetric changes. Its strength was also significantly enhanced. But when forming density exceeded $320 \mathrm{~kg} / \mathrm{m}^{3}$, the volumetric contractivity started to increase with increasing density, and the horizontal failure strength began to gradually decline. The reason is that the straw fiber had been destroyed by the external force. The fibrous structure began to collapse and lose part of the self-adhesive ability. So after unloading the external force, its strength will start to reduce, and the volume will also have a great change due to the flexibility of the straw itself.

As shown in Fig. 4c, the natural moisture content was negatively correlated with the forming density. This is because, with the increase of the density, the pores between the straw fibers become smaller and smaller, the water stored by the straw also decreased. At the same time, it could be seen that when the forming density exceeded $320 \mathrm{~kg} / \mathrm{m}^{3}$, the natural moisture content was still decreasing, but the trend was relatively gentle. In summary, the forming density should be $320 \mathrm{~kg} / \mathrm{m}^{3}$ as the central point of the Box-Behnken experiment, and the test range should be in the range 280 to $360 \mathrm{~kg} / \mathrm{m}^{3}$. 
a)

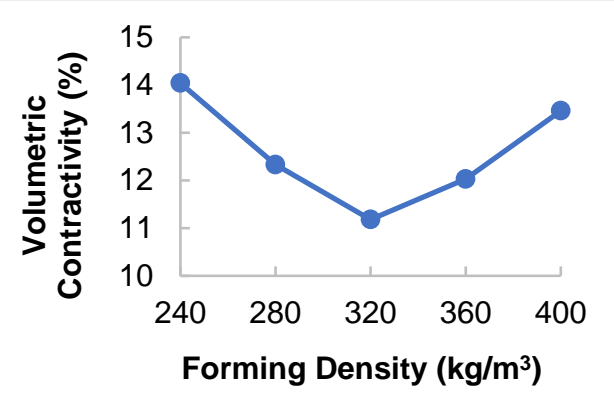

c)

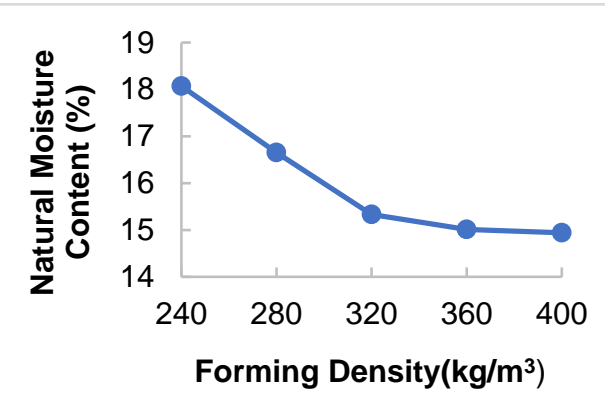

b)

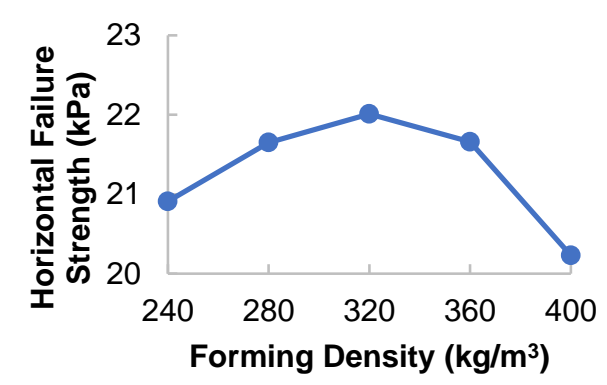

Fig. 4. Effect of forming density on a) volumetric contractivity, b) horizontal failure strength, and c) natural moisture content of the straw block

In order to study the influence of vertical pressure on the quality parameters of the straw block, the forming density was set as $320 \mathrm{~kg} / \mathrm{m}^{3}$, and the pressure-holding time was set as $30 \mathrm{~s}$ for the single factor test. According to Fig. 5, when the vertical pressure increased, the volumetric contractivity and natural moisture content of the straw block decreased gradually.

a)

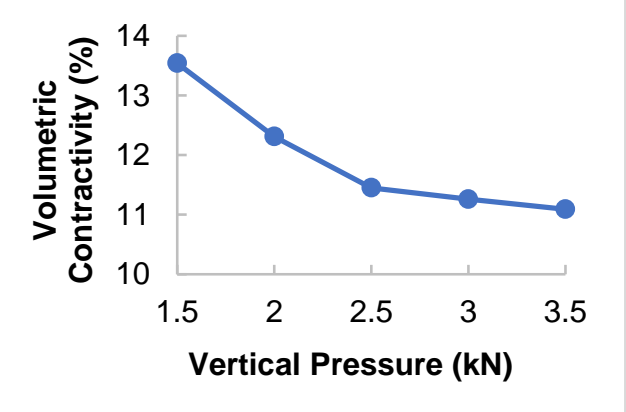

c)

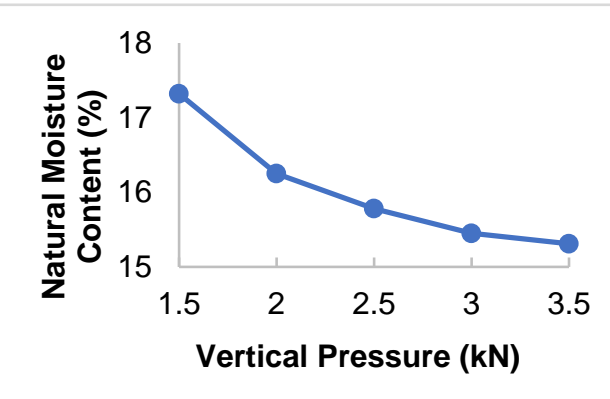

b)

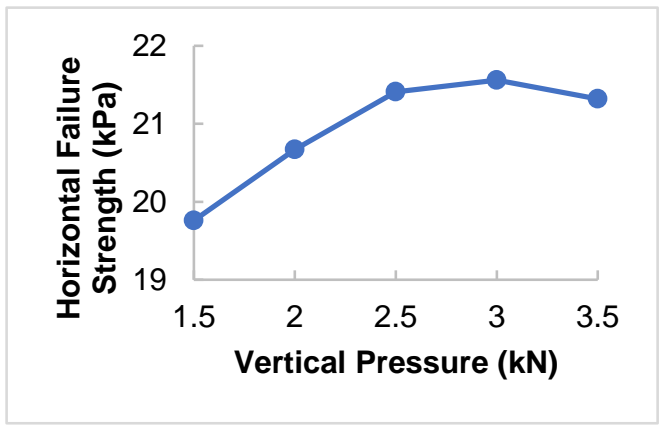

Fig. 5. Effect of vertical pressure on a) volumetric contractivity, b) horizontal failure strength and c) natural moisture content of the straw block 
The horizontal failure strength increased at first and reached the maximum when the vertical pressure was $3 \mathrm{kN}$, and then it decreased gradually. This is because when the straw is extruded by the external force, the self-adhesive fibers will be closely bonded together to form a dense structure. The greater the external force is, the tighter the structure is. Therefore, the pore volume of the fibers will be smaller, and less water can be stored. This phenomenon leads to the continuous decline of the natural moisture content. At the same time, the volume of the straw block will be more stable, and the horizontal failure strength will increase. However, when the vertical pressure exceeded $3 \mathrm{kN}$, the straw fiber had been destroyed by the external force, and part of the self-adhesive ability had lost, leading to the decrease of the horizontal failure strength. Therefore, in conclusion, $3 \mathrm{kN}$ should be selected as the central point of the Box-Behnken test for vertical pressure, and the test range should be 2.5 to $3.5 \mathrm{kN}$.

In order to study the influence of pressure-holding time on the quality parameters of straw blocks, the forming density was set as $320 \mathrm{~kg} / \mathrm{m}^{3}$ and the vertical pressure was set as $3 \mathrm{kN}$ for the single-factor test. According to Fig. 6a, the volumetric contractivity of the straw block decreased with the increase of pressure-holding time. Increasing the pressureholding time can effectively avoid the elastic deformation of straw in a short time, and the pressing effect is better so that the bond between straw fibers is closer to restrain the volumetric contractivity of straw blocks. As can be seen from Figs. $6 \mathrm{~b}$ and $6 \mathrm{c}$, the curve of pressure-holding time is gentle, indicating that the pressure-holding time has little influence on the horizontal failure strength and natural moisture content, but both reach their maximum and minimum respectively when the pressure-holding time is $30 \mathrm{~s}$. Considering the actual production efficiency, $30 \mathrm{~s}$ will be selected as the central point of the Box-Behnken test, and the test range is 10 to $50 \mathrm{~s}$.

a)

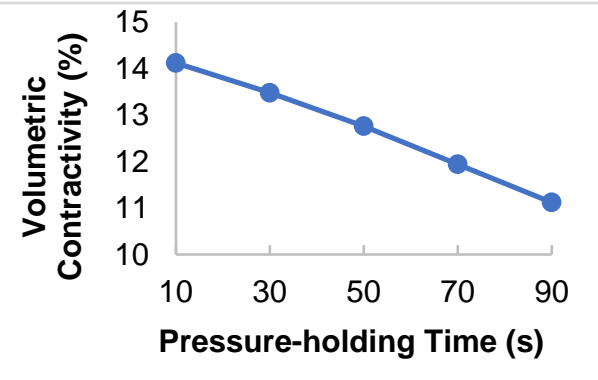

c)

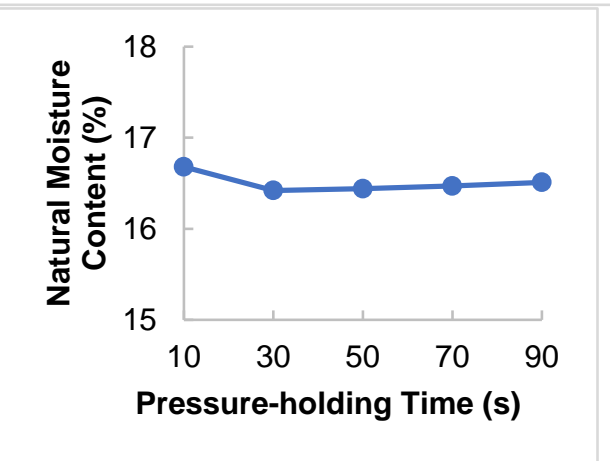

b)

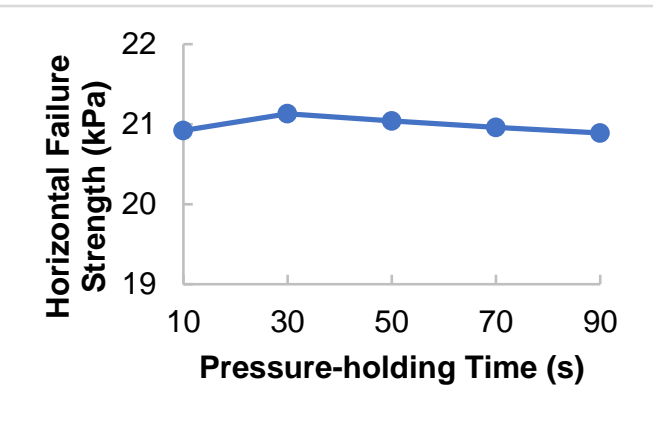

Fig. 6. Effect of pressure-holding time on a) volumetric contractivity, b) horizontal failure strength, and c) natural moisture content of the straw block 


\section{Box-Behnken Experimental Results and Model Building}

The Box-Behnken experimental design was introduced to study the influence of three variables (the forming density, vertical pressure, and pressure-holding time) on the tested small-size rice straw molding processes. The operational conditions were assayed and the experimental results of the three responses were analyzed, i.e., the volumetric contractivity, horizontal failure strength, and natural moisture content, as shown in Table 2. The volumetric contractivity ranged from $11.17 \%$ to $14.96 \%$, the horizontal failure strength ranged from 18.86 to $22.00 \mathrm{kPa}$, and the natural moisture content ranged from $14.97 \%$ to $18.21 \%$.

Based on the BBD experiment results, Design-Expert 10 software was used to analyze the data. A multivariable regression fitting model was chosen to achieve a ternary quadric model of the forming density $\left(X_{1}\right)$, vertical pressure $\left(X_{2}\right)$, and the pressure-holding time $\left(X_{3}\right)$, as they relate to the volumetric contractivity $(\eta)$, horizontal failure strength $(H F S)$, and natural moisture content $(N M C)$. The equations of each model are shown as Eqs. 6, 7, and 8, respectively,

$\eta=11.57+0.18 X_{1}-0.19 X_{2}-0.15 X_{3}-0.13 X_{1} X_{2}-0.062 X_{1} X_{3}-0.067 X_{2} X_{3}+$

$2.25 X_{1}^{2}-0.15 X_{2}^{2}+0.41 X_{3}^{2}$

$H F S=21.1-0.31 X_{1}+0.31 X_{2}+0.12 X_{3}+0.11 X_{1} X_{2}-0.025 X_{1} X_{3}-0.005 X_{2} X_{3}-$ 1.62 $X_{1}^{2}+0.94 X_{2}^{2}-0.43 X_{3}^{2}$

$N M C=16.22-1.27 X_{1}-0.26 X_{2}+0.11 X_{3}+0.0025 X_{1} X_{2}+0.035 X_{1} X_{3}-$ $0.005 X_{2} X_{3}+0.51 X_{1}^{2}-0.14 X_{2}^{2}+0.11 X_{3}^{2}$

where the variables are the same as previously defined.

Table 2. Experimental Parameters and the Response Numerical Results

\begin{tabular}{|c|c|c|c|c|c|c|}
\hline Sample & $\begin{array}{c}\text { Forming } \\
\text { density }\end{array}$ & $\begin{array}{c}\text { Vertical } \\
\text { Pressure }\end{array}$ & $\begin{array}{c}\text { Pressure- } \\
\text { holding time }\end{array}$ & $\begin{array}{c}\text { Volumetric } \\
\text { Contractivity } \\
(\%)\end{array}$ & $\begin{array}{c}\text { Horizontal } \\
\text { Failure } \\
\text { Strength } \\
(\mathrm{kPa})\end{array}$ & $\begin{array}{c}\text { Natural } \\
\text { Moisture } \\
\text { Content } \\
(\%)\end{array}$ \\
\hline 1 & -1 & -1 & 0 & 13.54 & 20.71 & 17.93 \\
\hline 2 & -1 & 0 & -1 & 13.82 & 19.31 & 18.21 \\
\hline 3 & -1 & 0 & 1 & 14.07 & 19.02 & 18.01 \\
\hline 4 & -1 & 1 & 0 & 14.26 & 21.20 & 17.78 \\
\hline 5 & 0 & -1 & -1 & 11.17 & 21.49 & 16.35 \\
\hline 6 & 0 & -1 & 1 & 11.28 & 21.23 & 16.65 \\
\hline 7 & 0 & 1 & -1 & 11.61 & 21.76 & 15.74 \\
\hline 8 & 0 & 1 & 1 & 12.14 & 22.00 & 16.02 \\
\hline 9 & 1 & -1 & 0 & 14.18 & 19.43 & 15.39 \\
\hline 10 & 1 & 0 & -1 & 14.57 & 18.86 & 15.61 \\
\hline 11 & 1 & 0 & 1 & 14.80 & 19.05 & 15.83 \\
\hline 12 & 1 & 1 & 0 & 14.96 & 20.38 & 14.97 \\
\hline 13 & 0 & 0 & 0 & 11.54 & 21.14 & 16.32 \\
\hline 14 & 0 & 0 & 0 & 11.58 & 21.26 & 15.94 \\
\hline 15 & 0 & 0 & 0 & 11.53 & 21.20 & 16.01 \\
\hline 16 & 0 & 0 & 0 & 11.61 & 21.05 & 16.49 \\
\hline 17 & 0 & 0 & 0 & 11.49 & 20.88 & 16.33 \\
\hline
\end{tabular}




\section{Model Adequacy}

The ANOVA for the response surface quadratic model of the volumetric contractivity, horizontal failure strength, and natural moisture (within the significant level of $\alpha=0.05$ ), are shown in Tables 3, 4, and 5, respectively.

Table 3. ANOVA for the Response Surface Quadratic Model of the Volumetric Contractivity

\begin{tabular}{|c|c|c|c|c|c|}
\hline Source & sos & DOF & MS & F-value & $p$-value \\
\hline Model & 33.64 & 9 & 3.74 & 1359.13 & $<0.0001$ \\
\hline $\mathrm{X}_{1}$ & 0.99 & 1 & 0.99 & 361.47 & $<0.0001$ \\
\hline$X_{2}$ & 0.98 & 1 & 0.98 & 356.36 & $<0.0001$ \\
\hline $\mathrm{X}_{3}$ & 0.16 & 1 & 0.16 & 57.02 & 0.0001 \\
\hline $\mathrm{X}_{1} \mathrm{X}_{2}$ & 0.0009 & 1 & 0.0009 & 0.33 & 0.5852 \\
\hline $\mathrm{X}_{1} \mathrm{X}_{3}$ & 0.0001 & 1 & 0.0001 & 0.036 & 0.8542 \\
\hline $\mathrm{X}_{2} \mathrm{X}_{3}$ & 0.044 & 1 & 0.044 & 16.04 & 0.0052 \\
\hline $\mathrm{X}_{1} \mathrm{X}_{1}$ & 31.27 & 1 & 31.27 & 11369.38 & $<0.0001$ \\
\hline $\mathrm{X}_{2} \mathrm{X}_{2}$ & 0.0067 & 1 & 0.0067 & 2.45 & 0.1615 \\
\hline $\mathrm{X}_{3} \mathrm{X}_{3}$ & 0.0067 & 1 & 0.0067 & 2.45 & 0.1615 \\
\hline Residual & 0.019 & 7 & 0.0028 & - & - \\
\hline Lack of Fit & 0.011 & 3 & 0.0036 & 1.65 & 0.3127 \\
\hline Pure Error & 0.0086 & 4 & 0.0021 & - & - \\
\hline Cor Total & 33.66 & 16 & - & - & - \\
\hline \multicolumn{2}{|c|}{$\mathrm{R}^{2}=0.9994$} & \multicolumn{2}{|c|}{$R_{\text {Adj }}^{2}=0.9987$} & \multicolumn{2}{|c|}{ C.V. $\%=0.41$} \\
\hline
\end{tabular}

Table 4. ANOVA for the Response Surface Quadratic Model of the Horizontal Failure Strength

\begin{tabular}{|c|c|c|c|c|c|}
\hline Source & sos & DOF & MS & F-value & $\mathrm{p}$-value \\
\hline Model & 16.78 & 9 & 1.86 & 28.32 & 0.0001 \\
\hline $\mathrm{X}_{1}$ & 0.79 & 1 & 0.79 & 12.06 & 0.0104 \\
\hline $\mathrm{X}_{2}$ & 0.77 & 1 & 0.77 & 11.68 & 0.0112 \\
\hline $\mathrm{X}_{3}$ & 0.12 & 1 & 0.12 & 1.82 & 0.2189 \\
\hline $\mathrm{X}_{1} \mathrm{X}_{2}$ & 0.053 & 1 & 0.053 & 0.80 & 0.3998 \\
\hline $\mathrm{X}_{1} \mathrm{X}_{3}$ & 0.0025 & 1 & 0.0025 & 0.038 & 0.8510 \\
\hline $\mathrm{X}_{2} \mathrm{X}_{3}$ & 0.0001 & 1 & 0.0001 & 0.0015 & 0.9700 \\
\hline $\mathrm{X}_{1} \mathrm{X}_{1}$ & 11.02 & 1 & 11.02 & 167.46 & $<0.0001$ \\
\hline $\mathrm{X}_{2} \mathrm{X}_{2}$ & 3.74 & 1 & 3.74 & 56.76 & 0.0001 \\
\hline $\mathrm{X}_{3} \mathrm{X}_{3}$ & 0.77 & 1 & 0.77 & 11.72 & 0.0111 \\
\hline Residual & 0.46 & 7 & 0.066 & - & - \\
\hline Lack of Fit & 0.37 & 3 & 0.12 & 5.65 & 0.0638 \\
\hline Pure Error & 0.088 & 4 & 0.022 & - & - \\
\hline Cor Total & 17.24 & 16 & - & - & - \\
\hline \multicolumn{2}{|c|}{$\mathrm{R}^{2}=0.9733$} & \multicolumn{2}{|c|}{$\mathrm{R}_{\mathrm{Adj}}^{2}=0.9389$} & \multicolumn{2}{|c|}{ C.V. $\%=1.25$} \\
\hline
\end{tabular}


Table 5. ANOVA for the Response Surface Quadratic Model of the Natural Moisture Content

\begin{tabular}{|c|c|c|c|c|c|}
\hline Source & SOS & DOF & MS & F-value & p-value \\
\hline Model & 14.71 & 9 & 1.63 & 28.19 & 0.0001 \\
\hline $\mathrm{X}_{1}$ & 12.83 & 1 & 12.83 & 221.21 & $<0.0001$ \\
\hline $\mathrm{X}_{2}$ & 0.55 & 1 & 0.55 & 9.42 & 0.0181 \\
\hline $\mathrm{X}_{3}$ & 0.097 & 1 & 0.097 & 1.67 & 0.2374 \\
\hline $\mathrm{X}_{1} \mathrm{X}_{2}$ & 0.0000 & 1 & 0.0000 & 0.0004 & 0.9840 \\
\hline $\mathrm{X}_{1} \mathrm{X}_{3}$ & 0.0049 & 1 & 0.0049 & 0.085 & 0.7797 \\
\hline $\mathrm{X}_{2} \mathrm{X}_{3}$ & 0.0001 & 1 & 0.0001 & 0.0017 & 0.9680 \\
\hline $\mathrm{X}_{1} \mathrm{X}_{1}$ & 1.10 & 1 & 1.10 & 19.05 & 0.0033 \\
\hline $\mathrm{X}_{2} \mathrm{X}_{2}$ & 0.086 & 1 & 0.086 & 1.48 & 0.2632 \\
\hline $\mathrm{X}_{3} \mathrm{X}_{3}$ & 0.055 & 1 & 0.055 & 0.96 & 0.3607 \\
\hline Residual & 0.41 & 7 & 0.058 & - & - \\
\hline Lack of Fit & 0.19 & 3 & 0.063 & 1.16 & 0.4295 \\
\hline Pure Error & 0.22 & 4 & 0.054 & - & - \\
\hline Cor Total & 15.12 & 16 & - & - & - \\
\hline \multicolumn{2}{r}{$\mathrm{R}^{2}=0.9732$} & $\mathrm{R}_{\text {Adj }}^{2}=0.9386$ & C.V.\% $=1.25$ \\
\hline Note: SOS Sum of squares; DOF = Degree of freedom; and MS = Mean square \\
\hline
\end{tabular}

As shown in Table 3, this model is statistically significant $(\mathrm{p}<0.0001)$, and the lack of fit is not significant $(\mathrm{p}>0.05)$. Meanwhile, the fitting correlation coefficient is $\mathrm{R}^{2}=$ 0.9994 , and the adjustment coefficient is $R_{A d j}^{2}=0.9987$, which indicates that the test results fit well with the model. This regression model can be used to guide the production of straw blocks and predict the volumetric contractivity of straw blocks after forming. According to Table 3, the order of influence of each significant term on the volumetric contractivity (from large to small) was forming density $\left(X_{1}\right)$, vertical pressure $\left(X_{2}\right)$, and pressure-holding time $\left(X_{3}\right)$.

Similarly, as shown in Table 4, this model was statistically significant ( $\mathrm{p}=0.0001)$, and the lack of fit was not significant $(\mathrm{p}>0.05)$. Meanwhile, the fitting correlation coefficient was $R^{2}=0.9733$, and the adjustment coefficient was $R_{\text {Adj }}^{2}=0.9389$, which indicates that the test results fit well with the model. This regression model can be used to guide the production of straw blocks and predict the horizontal failure strength of straw blocks after forming. According to Table 4, the order of influence of each significant term on the horizontal failure strength (from large to small) was forming density $\left(X_{1}\right)$, vertical pressure $\left(X_{2}\right)$, and pressure-holding time $\left(X_{3}\right)$.

As shown in Table 5, this model was statistically significant ( $\mathrm{p}=0.0001)$, and the lack of fit was not significant $(\mathrm{p}>0.05)$. Meanwhile, the fitting correlation coefficient was $\mathrm{R}^{2}=0.9732$, and the adjustment coefficient was $\mathrm{R}_{\text {Adj }}^{2}=0.9386$, which indicates that the test results fit well with the model. This regression model can be used to guide the production of straw blocks and predict the natural moisture content of straw blocks after forming. According to Table 5, the order of influence of each significant term on the horizontal failure strength (from large to small) was forming density $\left(X_{1}\right)$, vertical pressure $\left(X_{2}\right)$, and pressure-holding time $\left(X_{3}\right)$ 


\section{Analysis of the Interaction Between the Parameters}

The contour map obtained through the analysis of Expert Design 10 software could reflect whether the interaction between the two factors has a significant impact on the process parameters. As shown in Fig. 7, the contour plot of the interaction between the forming density and pressure-holding time on the horizontal failure strength of the straw block is elliptical, indicating that the interaction of these two parameters had a significant impact on the horizontal failure strength.

When the vertical pressure was constant, the horizontal failure strength of straw blocks increased at first and then decreased gradually with the forming density and the pressure-holding time increasing. Meanwhile, the slope of the forming density was larger, indicating that the influence of the forming density on the horizontal failure strength was more significant.

a)

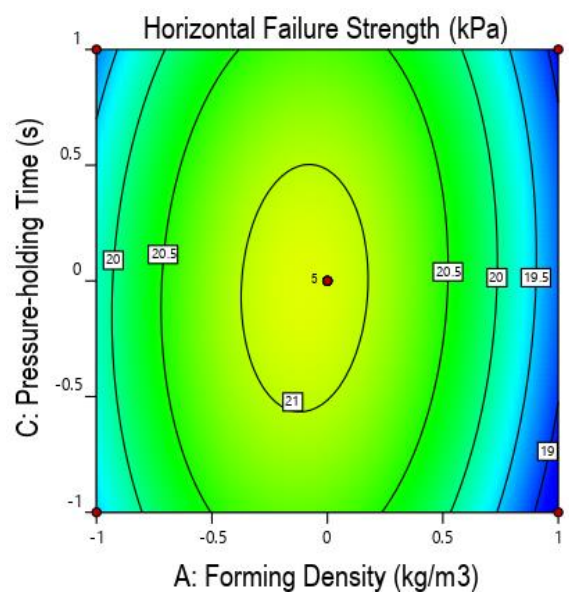

b)

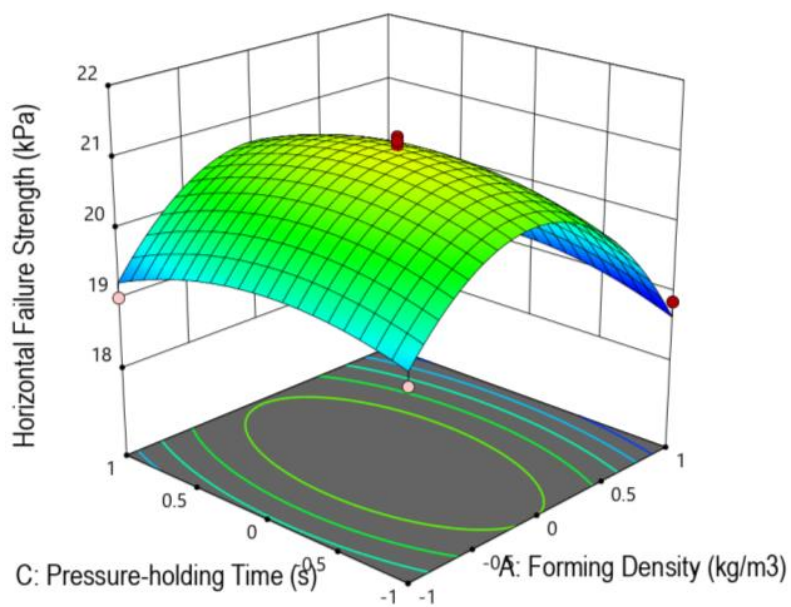

Fig. 7. a) Contour map and b) graphic model of interaction between forming density and pressure - holding time

\section{Parameter Optimization and Testing}

To improve the service life of the straw blocks, smaller volumetric contractivity, higher horizontal failure strength, and lower natural moisture content are required. Therefore, the volumetric contractivity could be set to its minimum value, while the horizontal failure strength is set to its maximum value, and the natural moisture content is set to its minimum value. By solving the formula in Design Expert, the optimal technology parameters were obtained when the forming density was $319.7 \mathrm{~kg} / \mathrm{m}^{2}$, the vertical pressure was $2.5 \mathrm{kN}$, and the pressure-holding time was $33.7 \mathrm{~s}$. Under these conditions, the predicted value of the volumetric contractivity was $11.17 \%$, the HFS was $21.74 \mathrm{kPa}$, and the NMC was $16.37 \%$.

To verify the reliability of the predicted results of the model, the parameters under the optimized conditions were used to carry out the verification test. The results are shown in Table 6. The relative deviation between the average values of the test and the predicted values of the volumetric contractivity, horizontal failure strength, and natural moisture content were $2.29 \%, 4.02 \%$, and $7.41 \%$, respectively, which are all less than $10 \%$. The experimental value and the predicted value were highly consistent. Therefore, the model was judged to be reliable. 
Table 6. Results of the Parameter Optimization Verification Test

\begin{tabular}{|c|c|c|c|}
\hline & $\begin{array}{c}\text { Volumetric } \\
\text { Contractivity }(\%)\end{array}$ & $\begin{array}{c}\text { Horizontal Failure } \\
\text { Strength }(\mathrm{kPa})\end{array}$ & $\begin{array}{c}\text { Natural Moisture } \\
\text { Content (\%) }\end{array}$ \\
\hline Sample 1 & 9.92 & 23.36 & 15.32 \\
\hline Sample 2 & 10.72 & 21.85 & 15.63 \\
\hline Sample 3 & 11.56 & 22.63 & 14.76 \\
\hline Sample 4 & 10.66 & 21.17 & 14.97 \\
\hline Sample 5 & 11.74 & 24.26 & 15.51 \\
\hline Average of the samples & 10.92 & 22.65 & 15.24 \\
\hline Calculation via models & 11.17 & 21.74 & 16.37 \\
\hline Related deviation (\%) & 2.29 & 4.02 & 7.41 \\
\hline
\end{tabular}

\section{CONCLUSIONS}

1. By reducing the water consumption of straw pretreatment and mechanical stirring, the chemical waste liquid produced during straw block production can be reduced while the softening effect is guaranteed, and the pretreatment efficiency can be accelerated.

2. The order of influence of each factor on the quality parameters of the straw block (from large to small) is: forming density, vertical pressure, and pressure-holding time. The forming density of straw blocks has the most significant effect on the forming quality. With the increase of the density, the volumetric contractivity decreases first and then increases, while the horizontal failure strength increases first and then decreases, and the natural moisture content decreases gradually. The second is the vertical pressure. When the vertical pressure increases, the volumetric contractivity, and natural moisture content decrease gradually, and the horizontal failure strength increases first and then decreases. The smallest effect is the pressure-holding time. When the holding time increases, the volumetric contractivity of straw blocks decreases gradually, but the horizontal failure strength and natural moisture content do not change significantly.

3. The interaction between forming density and pressure-holding time has a significant effect on the horizontal failure strength of the straw block. When the vertical pressure is constant, the horizontal failure strength increases first and then decreases gradually with the increase of forming density and pressure-holding time. Meanwhile, the slope of the forming density is larger, which indicates that the influence of the forming density is more significant.

4. The optimal combination of straw block forming processes was obtained by response surface methodology (RSM). Forming density was $319.7 \mathrm{~kg} / \mathrm{m}^{2}$, vertical pressure was $2.5 \mathrm{kN}$, and pressure-holding time was $33.7 \mathrm{~s}$. Under these conditions, the predicted value of volumetric contractivity was $11.2 \%$, the horizontal failure strength was 21.8 $\mathrm{kPa}$, and the natural moisture content was $16.4 \%$. At the same time, it was found that the model was close to the predicted value and was highly reliable after the verification test. The model can be used to guide the industrial production of the straw block. 


\section{ACKNOWLEDGMENTS}

This work was funded by the Chongqing Technology Innovation and Application Development Project (cstc2019jscx-gksbX0118).

\section{REFERENCES CITED}

Asdrubali, F., D'Alessandro, F., and Schiavoni, S. (2015). "A review of unconventional sustainable building insulation materials," Sustain Materials and Technologies 4, 117. DOI: 10.1016/j.susmat.2015.05.002

Ashour, T. (2003). The Use of Renewable Agricultural By-Products as Building Materials, Ph.D. Dissertation, Zagazig University, Zajazic, Egypt.

Bi, Y., Wang, H., Wang, D., Gao, C., and Wang, Y. (2011). "Estimation and utilization of rice straw resources in China," Chinese Agricultural Science Bulletin 27(15), 137143. DOI: $10.3969 / \mathrm{j} .1$ issn.1002-1302.2012.01.114

Carfrae, J. (2011). The Moisture Performance of Straw Bale Construction in a Temperate Maritime Climate, Ph.D. Dissertation, University of Plymouth, Plymouth, England.

Chaussinand, A., Scartezzini, J. L., and Nik, V. (2015). "Straw bale: A waste from agriculture, a new construction material for sustainable buildings," Energy Procedia 78, 297-302. DOI: 10.1016/j.egypro.2015.11.646

Conti, L., Barbari, M., and Monti, M. (2016). "Steady-state thermal properties of rectangular straw-bales (RSB) for building," Buildings 6(4), 44-57. DOI: 10.3390/buildings6040044

Costes, J.-P., Evrard, A., Biot, B., Keutgen, G., Daras, A., Dubois, S., Lebeau, F., and Courard, L. (2017). "Thermal conductivity of straw bales: Full size measurements considering the direction of the heat flow," Buildings 7(1), 11-26. DOI: 10.3390/buildings7010011

Food and Agriculture Organization of the United Nations (FAO) (2019). "FAOSTAT. Food and agriculture data," (http://www.fao.org/faostat/en/\#data/QC), Accessed Oct. 2019.

Garas, G. L., Allam, M. E., El Kady, H. M., and El Alfy, A. H. (2009). "Compressibility of single unrendered rice straw bales: Characteristics of bales used for building," ARPN Journal of Engineering and Applied Sciences 4, 84-90.

Goodhew, S., and Griffiths, R. (2004). "Sustainable earth walls to meet the building regulations," Energy and Buildings 37(5), 451-459. DOI: 10.1016/j.enbuild.2004.08.005

Han, X., Luo, Q., Bao, A., and Luo, S. (2019). "Research on the mechanism of improving rice straw self-bonding via $\mathrm{NaOH}$ solution pretreatment," BioResources 14(4), 93529363. DOI: 10.15376/biores.14.4.9352-9363

Holzhueter, K., and Itonaga, K. (2014). "The influence of passive ventilation on the interstitial hygrothermal environment of a straw bale wall," Journal of Asian Architecture and Building Engineering 13(1), 223-229. DOI: 10.3130/jaabe.13.223

Jones, B. (2009). Building with Straw Bales: A Practical Guide for the UK and Ireland, Green Books \& Resurgemonince Books, Totnes, UK. 
Kim, G., and Ward, M. (2019). The Peoples Republic of China Grain and Feed Annual 2018 (Report No. CH19022), USDA Foreign Agricultural Service.

Krick, B. (2008). Untersuchung von Strohballen und Strohballenkonstruktionen Hinsichtlich Ihrer Anwendung für ein Energiesparendes Bauen Unter Besonderer Berücksichtigung der Lasttragenden Bauweise [Investigation of Straw and Straw Bale Constructions with Regard to Their Application for Energy-saving Construction with Special Consideration of the Load-bearing Construction], Ph.D. Dissertation, Kassel University, Kassel, Germany.

Lecompte, T., and Le Duigou, A. (2017). "Mechanics of straw bales for building applications," Journal of Building Engineering 9, 84-90. DOI: 10.1016/j.jobe.2016.12.001

Li, L., Wang, Y., Zhang, Q., Li, J., Yang, X., and Jin, J. (2008). "Wheat straw burning and its associated impacts on Beijing air quality," Science China Earth Sciences 51 (3), 403-414. DOI: 10.1007/s11430-008-0021-8

Maraldi, M., Molari, L., Regazzi, N., and Molari, G. (2017). "Analysis of the parameters affecting the mechanical behaviour of straw bales under compression," Biosystems Engineering 160, 179-193. DOI: 10.1016/j.biosystemseng.2017.06.007

Palermo, M., Gil-Martin, L. M., Hernandez-Montes, E., and Aschheim, M. (2014). "Refined compression field theory for plastered straw bale walls," Construction and Building Materials 58, 101-110. DOI: 10.1016/j.conbuildmat.2014.02.004

Palumbo, M., Lacasta, A. M., Holcroft, N., Shea, A., and Walker, P. (2016). "Determination of hygrothermal parameters of experimental and commercial biobased insulation materials," Construction and Building Materials 124, 269-275. DOI: 10.1016/j.conbuildmat.2016.07.106

Schiavoni, S., D’Alessandro, F., Bianchi, F., and Asdrubali, F. (2016). "Insulation materials for the building sector: A review and comparative analysis," Renewable and Sustainable Energy Reviews 62, 988-1011. DOI: 10.1016/j.rser.2016.05.045

Sun, D., Bao, A., and Chen, L. (2020). "Study on softening effect of $\mathrm{NaOH}$ pretreatment on rice straw," Journal of Southwest China Normal University (Natural Science Edition) 2020(2), 73-78. DOI: 10.13718/j.cnki.xsxb.2020.02.011

Thomson, A., and Walker, P. (2014). "Durability characteristics of straw bales in building envelopes," Construction and Building Material 68, 135-141. DOI: 10.1016/j.conbuildmat.2014.06.041

Vardy, S. P., and MacDougall, C. (2013). "Concentric and eccentric compression experiments of plastered straw bale assemblies," Journal of Structural Engineering 139(3), 448-461. DOI: 10.1061/(ASCE)ST.1943-541X.0000668

Vèjelienè, J. (2012). "Processed straw as effective thermal insulation for building envelope constructions," Engineering Structures and Technologies 4(3), 96-103. DOI: 10.3846/2029882X.2012.730286

Wang, J., Zhu, S., Liu, J., Wu, Y., and Ye, J. (2006). "Study on the chemical basis of chemical pretreatment to change the ultrastructure of rice straw," Journal of Zhejiang University (SCIENCE EDITION) 2006(4), 424-428.

Wei, K., Lv, C., Chen, M., Zhou, X., Dai, Z., and Shen, D. (2015). "Development and performance evaluation of a new thermal insulation material from rice straw using high frequency hot-pressing," Energy and Buildings 87, 116-122. DOI: 10.1016/j.enbuild.2014.11.026 
Yin, X., Lawrence, M., Maskell, D., and Chang, W.-S. (2018). "Construction and monitoring of experimental straw bale building in northeast China," Construction and Building Materials 183, 46-57. DOI: 10.1016/j.conbuildmat.2018.05.283

Article submitted: October 26, 2020; Peer review completed: December 19, 2020;

Revised version received: February 18, 2021; Accepted: February 19, 2021; Published:

February 24, 2021.

DOI: $10.15376 /$ biores.16.2.2756-2773 